\title{
Planar Optical Waveguides Based on Thin ZnO Layers
}

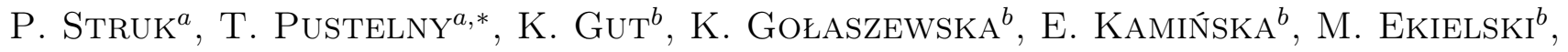 \\ I. PASTERnAK ${ }^{b}$, E. Eusakowska ${ }^{c}$ AND A. PiotrowskA ${ }^{b}$ \\ ${ }^{a}$ Department of Optoelectronics at Silesian University of Technology \\ Krzywoustego 2, 44-100 Gliwice, Poland \\ ${ }^{b}$ Institute of Electron Technology, al. Lotników 32/46, 02-668 Warsaw, Poland \\ ${ }^{c}$ Institute of Physics, PAS, al. Lotników 32/46, 02-668 Warsaw, Poland
}

\begin{abstract}
The paper quotes the results of investigations concerning planar optical waveguides with a high value of the refractive index, achieved basing on a broad-band gap semiconductor $\mathrm{ZnO}$, deposited on glass or quartz substrates. The investigations were focused on the properties of the waveguides, determining the modal characteristics, the attenuation coefficient and the structure of the surface.
\end{abstract}

PACS numbers: 42.25.Hz, 42.25.-p, 42.70.-a, 42.82.-m, 42.82.Et, 68.35.Ct

\section{Introduction}

Zinc oxide $\mathrm{ZnO}$ is a semiconductor material with a wide broad-band gap of $3.4 \mathrm{eV}$. It displays attractive properties permitting to apply it in sensor techniques as well as in systems of integrated optics. Data quoted in literature indicate that it is transparent in a visible range. It is characterized by a high value of the refractive index $(n \approx 2)$ [1-6], which is a favorable feature of the waveguide in systems of integrated optics [3]. The primary aim of the investigations is to develop in future a photonic sensor structure attained in compliance with the techniques of integrated optics applied as sensors of selected gases, e.g. $\mathrm{NH}_{3}, \mathrm{NO}_{x}, \ldots$ Gas sensors constructed on the basis of integrated optics are particularly desirable in environments liable to considerable hazards of explosion, i.e. in industry [1]. An innovation of the solution suggested by us is the construction of a sensor structure in compliance with the techniques of integrated optics, comprising a waveguide layer, a sensor layer and input-output elements, viz. Bragg's gratings, all mounted on common substrate. The subject matter of the present paper is to investigate the optical waveguide properties of $\mathrm{ZnO}$ layers depending on the applied deposition technology and their thermal treatments [7-18].

\section{Planar optical waveguide}

The fundamental property of planar waveguide structures is the relation between the number of the waveguide modes in the function of the layer thickness propagating in the structure and its refractive index. It had

\footnotetext{
* corresponding author; e-mail: tadeusz.pustelny@polsl.pl
}

been assumed that single-mode structures would permit to propagate only the modes TE0 and TMO and also multimode structures for TE0, TM0, as well as TE1 and TM1. Comprehensive numerical investigations of waveguide structures were carried out. The calculations were realized applying the software OptivaveMode 2D Solver.

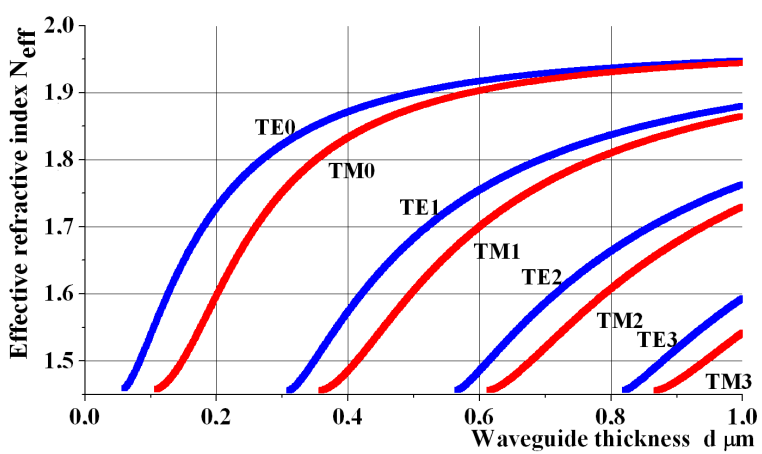

Fig. 1. Effective refractive index $N_{\text {eff }}$ in the function of the thickness of the waveguide layer $d$.

In order to find the required thickness of the layer, the dependence of the effective refractive index in the function of the layer thickness for an electromagnetic wave with a wavelength of $\lambda=677 \mathrm{~nm}$, was determined, assuming that the waveguide structure consists of $\mathrm{ZnO}$ with a refractive index value $n_{\mathrm{w}}=1.975$, deposited on a quartz substrate with a refractive index $n_{\mathrm{s}}=1.456$. The refractive index of the environment amounted to $n_{\mathrm{c}}=1.000$ (Fig. 1). In result of the analysis of the characteristics quoted above, single-mode waveguide layers were produced with a thickness of $d=300 \mathrm{~nm}$, as well as multimode waveguides with a thickness of $d=500 \mathrm{~nm}$. 


\section{Experiment}

The waveguide layers of $\mathrm{ZnO}$ were made by means of the method of reactive cathode magnetron sputtering in the system Leybold Z-400 on quartz substrates. The deposition processes were run in the RF mode. $\mathrm{ZnO}$ powder of $99.99 \%$ purity was vaporized from the ceramic target in an atmosphere which was a mixture of oxygen $\mathrm{O}_{2}(70 \%)$ and argon $\mathrm{Ar}(30 \%)$, at a total pressure $p_{\mathrm{Ar}+\mathrm{O}}=1 \times 10^{-2}$ mbar and a partial pressure of the oxygen $p_{\mathrm{O}}=3 \times 10^{-3}$ mbar for the intensity of electric current flowing through the cathode with a value of $I_{\mathrm{c}}=140 \mathrm{~mA}$. The rate of deposition amounted to $<20 \mathrm{~nm} / \mathrm{min}$. The thickness of the obtained layers was $d \approx 300 \mathrm{~nm}$ or $d \approx 500 \mathrm{~nm}$. During the depositing processes of waveguide layers the substrates were not additionally heated. After their deposition the layers were subjected to a two-stage process of soaking, making use of the rapid thermal annealing (RTA) technique, first for ten minutes in a nitrogen atmosphere at $400^{\circ} \mathrm{C}$ in order to eliminate mechanical strain, and then in oxygen at a temperature of $500^{\circ} \mathrm{C}$ or $600^{\circ} \mathrm{C}$.

The metrological stage consisted in the determination of: (i) the morphology of the surface of $\mathrm{ZnO}$ layers by applying the AFM technique (using Nanoscope IIIa type), (ii) the refractive index and thickness of the layers by means of the ellipsometer (SENTECH SE400) at a $632.8 \mathrm{~nm}$ wavelength; (iii) the modal characteristics and (iv) the attenuation coefficient. The modal characteristics were determined on the measurement stand presented in Fig. 2a.

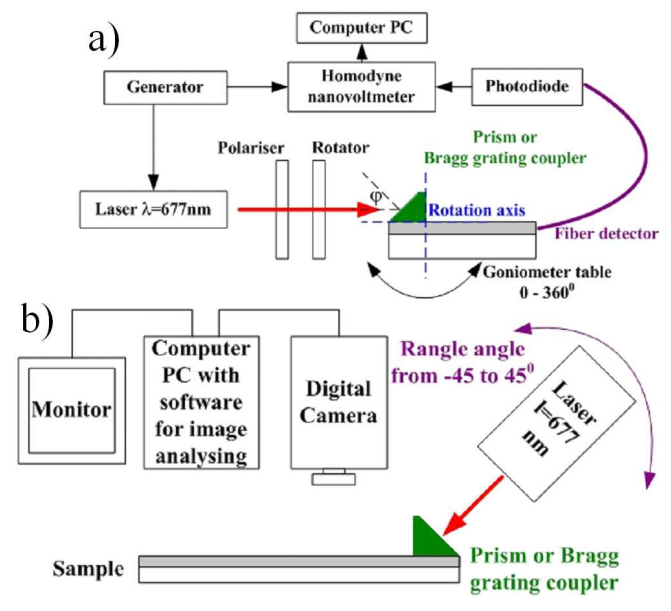

Fig. 2. Measurement stand for measuring: the modal spectrum (a), the attenuation coefficient (b).

The fundamental data of this measurement stand were following. Semiconductor laser emitted light with a wavelength $\lambda=677 \mathrm{~nm}$. The laser beam passes through a polarizer, and next through a rotator, fixing the state of polarization for TE or TM modes. The tested samples were placed on a rotating goniometric table. As an optical coupler a (BGO) $\mathrm{Bi}_{12} \mathrm{GeO}_{20}$ crystal prism was used with a refractive index of $n_{\mathrm{p}}=2.5407$. The optical signal from the tested sample was then passed by means of a detective fibre to the photodiode. In order to restrict the effect of optical and electrical noise and disturbances a homodyne nanovoltmeter was used. The signal from the homodyne is recorded in a PC computer.

The test stand for the determination of the attenuation coefficient (Fig. 2b) comprises a semiconductor laser $\lambda=$ $677 \mathrm{~nm}$. The light from the laser is passed through the prismatic coupler to the waveguide layer, where the light is attenuated and scattered. The image of the optical beam propagating in the planar waveguide is recorded by a digital camera and next subjected to digital processing making use of the software LabView [10].

\section{Results}

The first stage of the investigation consisted in the determination of the effect of RTA soaking on the morphology of the $\mathrm{ZnO}$ layers.

Layers of $\mathrm{ZnO}$ deposited on quartz or semiconducting substrates are, depending on the technology of their production, characterized by a structure with a considerably developed topography of the surface (Fig. 3). The observed irregularities of the $\mathrm{ZnO}$ surfaces amount in the case of their production by means of cathode magnetron sputtering to $\mathrm{rms}>20 \mathrm{~nm}[11]$. The process of soaking influences the quality of the surface of $\mathrm{ZnO}$ layers (their roughness). When $\mathrm{ZnO}$ layers are soaked at a temperature of $600^{\circ} \mathrm{C}$, the roughness reaches $\mathrm{rms} \approx 4 \mathrm{~nm}$. After soaking of the $\mathrm{ZnO}$ layers at a temperature of $700^{\circ} \mathrm{C}$ the roughness of the surfaces increased to $\mathrm{rms} \approx 6 \mathrm{~nm}$. This comparison leads to the conclusion that the process of soaking ought to be run at temperature not exceeding $600^{\circ} \mathrm{C}$. Table I quotes information about the thicknesses of the respective $\mathrm{ZnO}$ layers as well as their refractive indices. The refractive index of layers with a thickness of $\approx 300 \mathrm{~nm}$ amounts to $n=2.08$. In the case of layers whose thickness exceeds $500 \mathrm{~nm}$ the value of the refractive index is $n \approx 1.9$.

The next stage of investigations was the determination of the optical waveguide properties of the produced $\mathrm{ZnO}$ layers. An analysis of the determined modal characteristics permitted to verify the structure with respect to the number of propagating modes. The modal spectra of single-mode layers can be seen in Fig. 4, Fig. 5 and Fig. 6, and those of multi-mode layers in Fig. 7, Fig. 8 and Fig. 9. The effective refractive indices of the respective modes, determined basing on these spectra, were compared with numerically determined values presented in Fig. 1.

\subsection{Single-mode waveguide layers}

An analysis of the intensity of scattered light of the propagating mode as a function of the path of propagation in the waveguide permits to determine the attenuation coefficient of the mode [10]. This method was applied to determine the attenuation coefficients $\alpha$ in $\mathrm{ZnO}$ layers. The soaking of waveguide $\mathrm{ZnO}$ layers influenced 


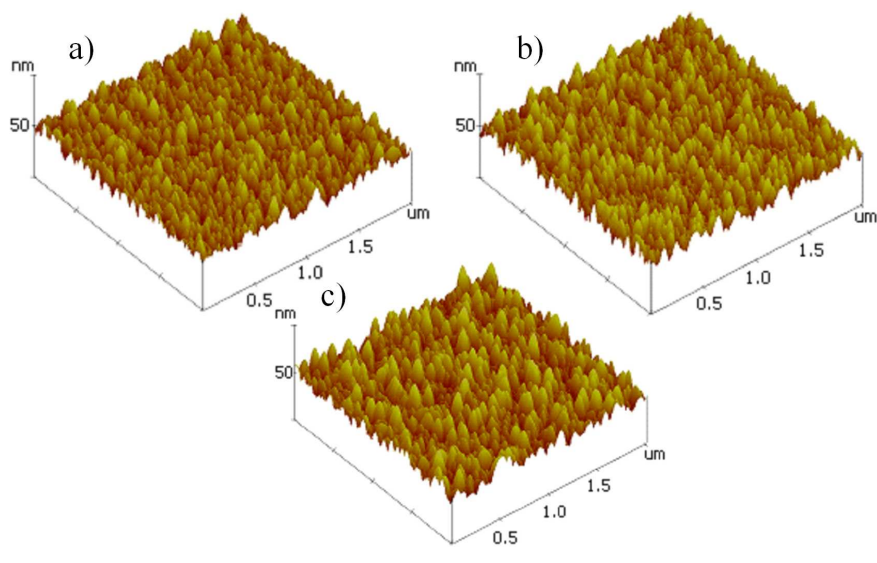

Fig. 3. Morphology of the $\mathrm{ZnO}$ layers: (a) without soaking, $\mathrm{rms}=4.3 \mathrm{~nm}$; (b) $T_{\max }=600^{\circ} \mathrm{C}, t=10 \mathrm{~min}$, $\mathrm{O}_{2}, \mathrm{rms}=4.2 \mathrm{~nm}$; (c) $T_{\max }=700^{\circ} \mathrm{C}, t=10 \mathrm{~min}, \mathrm{O}_{2}$, $\mathrm{rms}=6.3 \mathrm{~nm}$.

TABLE I

The thickness and refractive index of $\mathrm{ZnO}$ layers.

\begin{tabular}{|c|c|c|c|}
\hline Layer & RTA soaking & Thickness [nm] & Refractive index \\
\hline$\# 1$ & without soaking & 303 & 2.086 \\
\hline$\# 2$ & $\mathrm{O}_{2}-500^{\circ} \mathrm{C} / 10 \mathrm{~min}$ & 294 & 2.042 \\
\hline$\# 3$ & $\begin{array}{l}\mathrm{O}_{2}-500^{\circ} \mathrm{C} / 10 \mathrm{~min}, \\
\mathrm{O}_{2}-600^{\circ} \mathrm{C} / 10 \mathrm{~min}\end{array}$ & 306 & 2.084 \\
\hline$\# 5$ & $\mathrm{O}_{2}-500^{\circ} \mathrm{C} / 10 \mathrm{~min}$ & 548 & 1.947 \\
\hline$\# 6$ & $\begin{array}{l}\mathrm{O}_{2}-500^{\circ} \mathrm{C} / 10 \mathrm{~min}, \\
\mathrm{O}_{2}-500^{\circ} \mathrm{C} / 10 \mathrm{~min}\end{array}$ & 584 & 1.875 \\
\hline
\end{tabular}

the value of the attenuation coefficient $\alpha$. In the case of unsoaked layers \#1 the whole path of light propagation amounted to about $d \approx 3 \mathrm{~mm}$, which converted to the value of the attenuation coefficients, corresponding to $\alpha_{\mathrm{TE} 0} \approx 35 \mathrm{~dB} / \mathrm{cm}$ (Fig. 4). The $\mathrm{ZnO}$ waveguide layer \#1 was obtained without its soaking.

The $\mathrm{ZnO}$ waveguide layer $\# 2$ was soaked in an $\mathrm{O}_{2}$ atmosphere for about $10 \mathrm{~min}$ at a temperature $500^{\circ} \mathrm{C}$. It could be observed that the total distance of light propagation in it increased for the TE0 mode to about $4 \mathrm{~mm}$, which corresponds to the attenuation coefficients equal to: $\alpha_{\mathrm{TE} 0}=30 \mathrm{~dB} / \mathrm{cm}$ for TE 0 mode and $\alpha_{\mathrm{TM} 0}=$ $31 \mathrm{~dB} / \mathrm{cm}$ in the case of the TM0 mode (Fig. 5).

The most favourable results were obtained in the case of the $\mathrm{ZnO}$ layer $\# 3$, soaked for $10 \mathrm{~min}$ in an $\mathrm{N}_{2}$ atmosphere at a temperature of $400^{\circ} \mathrm{C}$, and next for $10 \mathrm{~min}$ in an $\mathrm{O}_{2}$ atmosphere, followed by soaking for $10 \mathrm{~min}$ at a temperature of $600^{\circ} \mathrm{C}$, also in an $\mathrm{O}_{2}$ atmosphere. In this case the distance of light propagation inside the $\mathrm{ZnO}$ waveguide layer amounts for the TE0 mode to $d \approx 7 \mathrm{~mm}$ (corresponding to an attenuation coefficient of $\alpha_{\mathrm{TE} 0}=14 \mathrm{~dB} / \mathrm{cm}, \alpha_{\mathrm{TM} 0}=18 \mathrm{~dB} / \mathrm{cm}$ (Fig. 6)). The process of soaking results in a considerable drop of the optical attenuation in the layer, and thus to an increased
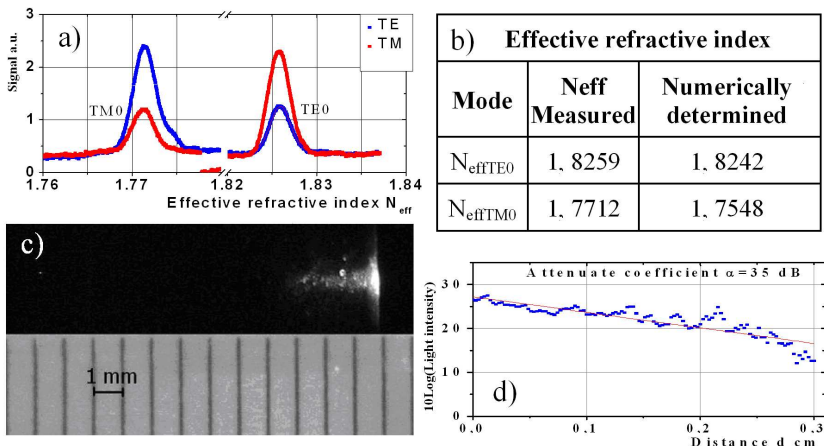

Fig. 4. Modal characteristic of $\mathrm{ZnO}$ waveguide \#1 excited by means of the prism method (a), table presents also the effective refractive index (b), propagation of light in a $\mathrm{ZnO}$ waveguide (c), attenuation coefficient $\alpha=35 \mathrm{~dB} / \mathrm{cm}$ (d).

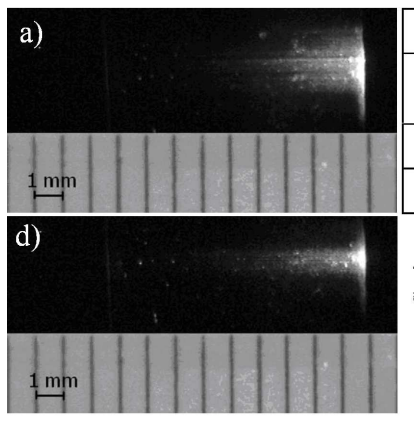

\begin{tabular}{|c|c|c|}
\hline c) Effective refractive index \\
\hline Mode & $\begin{array}{c}\text { Neff } \\
\text { Measured }\end{array}$ & $\begin{array}{c}\text { Numerically } \\
\text { determined }\end{array}$ \\
\hline $\mathrm{N}_{\text {effTE} 0}$ & 1.8030 & 1.8183 \\
\hline $\mathrm{N}_{\text {effTM }}$ & 1.7428 & 1.7448 \\
\hline
\end{tabular}
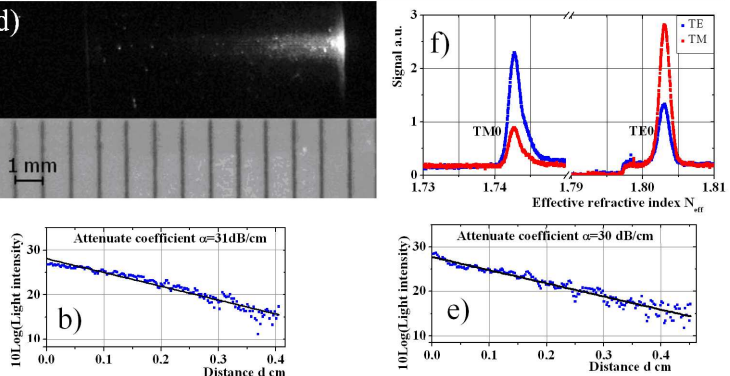

Fig. 5. Propagation of light in a $\mathrm{ZnO}$ waveguide $\# 2$ : (a) TE0, (d) TM0, (f) modal characteristic of the $\mathrm{ZnO}$ waveguide; attenuation coefficient: (b) TE0 $\alpha=30 \mathrm{~dB}$, (e) TM0 $\alpha=31 \mathrm{~dB}$; (c) table includes effective refractive index.

distance of the light propagation in the waveguide structure.

\subsection{Multimode layers}

In the case of unsoaked $\mathrm{ZnO}$ waveguide layers \#4 the distance of light propagation amounts to about $d \approx$ $3 \mathrm{~mm}$. Also in unsoaked $\mathrm{ZnO}$ layers with greater thickness constituting multimode structures, the attenuation coefficient was of considerable importance, e.g. concerning the mode TE it amounts to about $\alpha_{\mathrm{TE} 0}=38 \mathrm{~dB} / \mathrm{cm}$, whereas in the case of the TM0 mode it is $\alpha_{\mathrm{TM} 0}=$ $40 \mathrm{~dB} / \mathrm{cm}$ (Fig. 7).

Figure 8 presents the results of investigations concerning the $\mathrm{ZnO}$ layer $\# 5$, which was soaked for $10 \mathrm{~min}$ in $\mathrm{N}_{2}$ atmosphere at a temperature of $400^{\circ} \mathrm{C}$, and next for 10 min in an $\mathrm{O}_{2}$ atmosphere at a temperature of $500^{\circ} \mathrm{C}$. The attenuation coefficient in this layer amounted to $\alpha_{\text {TE0 }} \approx 30 \mathrm{~dB} / \mathrm{cm}$ (Fig. 8 and Table II). 

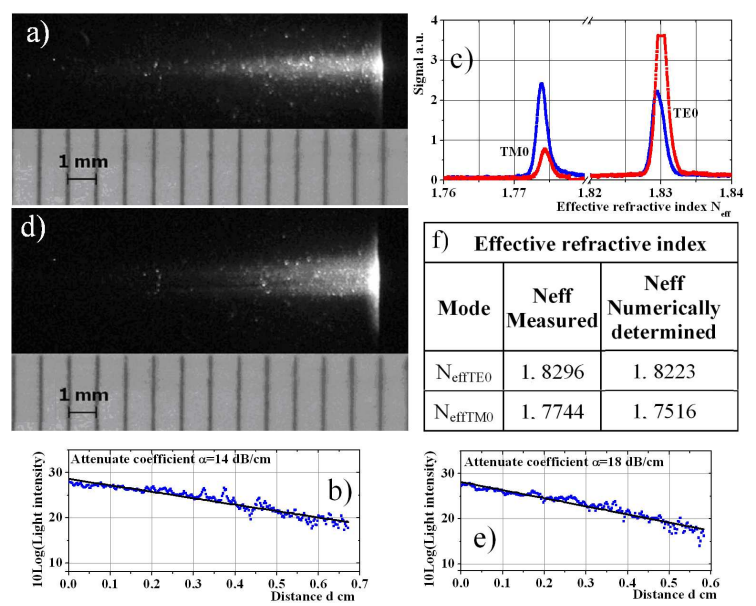

Fig. 6. Propagation of light in a $\mathrm{ZnO}$ waveguide \#3: (a) TE0, (d) TM0, (c) modal characteristic of the $\mathrm{ZnO}$ waveguide; attenuation coefficient: (b) TE0 $\alpha=14 \mathrm{~dB}$, (e) TM0 $\alpha=18 \mathrm{~dB}$; (f) table includes effective refractive index.
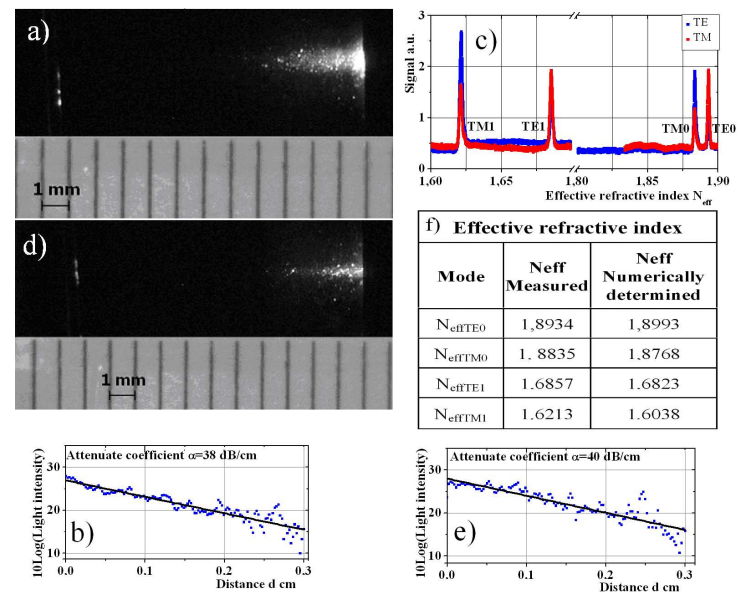

Fig. 7. Propagation of light in a $\mathrm{ZnO}$ waveguide \#4: (a) TE0, (d) TM0, (c) modal characteristic of the $\mathrm{ZnO}$ waveguide; attenuation coefficient: (b) TE0 $\alpha=38 \mathrm{~dB}$, (e) TM0 $\alpha=40 \mathrm{~dB}$; (f) table provides effective refractive index.

The most favourable optical transmission properties were attained in the case of $\mathrm{ZnO}$ layers $\# 6$, soaked for $10 \mathrm{~min}$ in $\mathrm{O}_{2}$ atmosphere at a temperature of $500^{\circ} \mathrm{C}$, followed by soaking for $10 \mathrm{~min}$ in an $\mathrm{O}_{2}$ atmosphere at a temperature of $600^{\circ} \mathrm{C}$. In such a case the attenuation coefficients amounted to: $\alpha_{\mathrm{TE} 0}=14 \mathrm{~dB} / \mathrm{cm}$ and $\alpha_{\mathrm{TM} 0}=$ $18 \mathrm{~dB} / \mathrm{cm}$ (Fig. 9 and Table III).

\section{Conclusions}

The chief aim of the presented investigations was to find out the possibilities of applying $\mathrm{ZnO}$ layers as optical waveguides in integrated optics. The first stage of the investigations permitted to determine the effect of
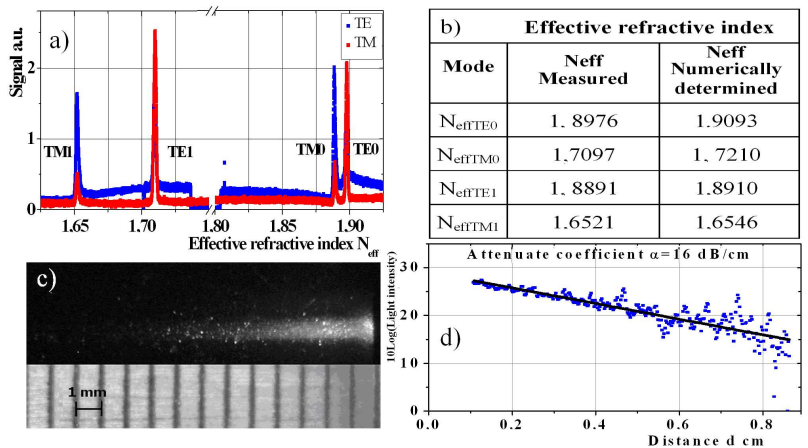

Fig. 8. Modal characteristic of $\mathrm{ZnO}$ waveguide \#5 (a); table quotes the effective refractive index (b); propagation of light in a $\mathrm{ZnO}$ waveguide (c); attenuation coefficient $\alpha=16 \mathrm{~dB}(\mathrm{~d})$.

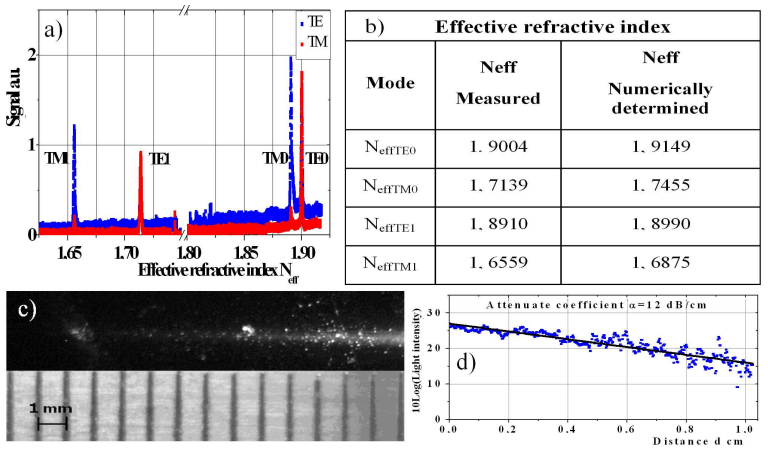

Fig. 9. Modal characteristic of the $\mathrm{ZnO}$ waveguide \#6 (a); table includes effective refractive index (b); propagation of light in the $\mathrm{ZnO}$ waveguide (c); attenuation coefficient $\alpha=12 \mathrm{~dB}(\mathrm{~d})$.

TABLE II

Attenuation coefficients of the investigated optical waveguide structures.

\begin{tabular}{c|c|c|c}
\hline \hline Structure & Soaking & \multicolumn{2}{|c}{ Attenuation of } \\
& & TE0 $[\mathrm{dB} / \mathrm{cm}]$ & $\mathrm{TE} 0[\mathrm{~dB} / \mathrm{cm}]$ \\
\hline$\# 1$ & unsoaking & 35 & - \\
$\# 2$ & $\mathrm{O}_{2}-500^{\circ} \mathrm{C} / 10 \mathrm{~min}$ & 30 & 31 \\
$\# 3$ & $\mathrm{O}_{2}-500^{\circ} \mathrm{C} / 10 \mathrm{~min}$, & 14 & 18 \\
& $\mathrm{O}_{2}-600^{\circ} \mathrm{C} / 10 \mathrm{~min}$ & &
\end{tabular}

TABLE III

Attenuation coefficient concerning the respective optical waveguide structures.

\begin{tabular}{|c|c|c|c|}
\hline \multirow[t]{2}{*}{ Structure } & \multirow[t]{2}{*}{ Soaking } & \multicolumn{2}{|c|}{ Attenuation of } \\
\hline & & TE0 $[\mathrm{dB} / \mathrm{cm}]$ & TE0 $[\mathrm{dB} / \mathrm{cm}]$ \\
\hline$\# 4$ & unsoaking & 38 & 40 \\
\hline$\# 5$ & $\mathrm{O}_{2}-500^{\circ} \mathrm{C} / 10 \mathrm{~min}$ & 16 & - \\
\hline$\# 6$ & $\begin{array}{l}\mathrm{O}_{2}-500^{\circ} \mathrm{C} / 10 \mathrm{~min}, \\
\mathrm{O}_{2}-500^{\circ} \mathrm{C} / 10 \mathrm{~min}\end{array}$ & 12 & - \\
\hline
\end{tabular}


the technological process of the production of $\mathrm{ZnO}$ layers on the optical waveguide properties of such structures. Light attenuation in the waveguides depends both on the internal structure of the materials (their heterogeneity) and the structure of their surfaces. The investigations have proved that in the case of thin waveguide layers the attenuation of the optical signal propagating in them increases rapidly with the roughness of the surface of the rms layer. In order to reduce the attenuation of the optical signal to a minimum, the $\mathrm{ZnO}$ layers were subjected to thermal treatment in the RTA process. Layers obtained without soaking were characterized by attenuation on the level of $35-40 \mathrm{~dB} / \mathrm{cm}$. The soaking of $\mathrm{ZnO}$ layers permitted to decrease the attenuation coefficient to about $10 \mathrm{~dB} / \mathrm{cm}$. Adequately performed thermal treatment may cause a reconstruction of the structure of the materials and reduce the roughness of the layer surfaces, and thus improve their optical properties.

\section{Acknowledgments}

The presented investigations were partly sponsored within the grant number N515 025 32/1887 of the Ministry of Science and Higher Education.

\section{References}

[1] P.V. Lambeck, Meas. Sci. Technol. 17, R93 (2006).

[2] C. Jagadish, S. Pearton, Zink Oxide, Thin Films and Nanostructures Processing, Properties, and Applications, Elsevier, New York 2006.

[3] T. Pustelny, Physical and Technical Aspects of Optoelectronic Sensors, Ed. SUT, Gliwice 2005, p. 86.
[4] R.G. Heideman, P.V. Lambeck, J.G.E. Gardeniers, Opt. Mater. 4, 741 (1995).

[5] W. Jakubik, E. Maciak, T. Pustelny, A. Stolarczyk, M. Urbanczyk, Mol. Quant. Acoust. 28, 125 (2007).

[6] T. Pustelny, E. Maciak, Z. Opilski, A. Piotrowska, E. Papis, K. Golaszewska, Europ. Phys. J.-Spec. Top. 154, 155 (2008).

[7] J. Ignac-Nowicka, T. Pustelny, E. Maciak, W. Jakubik, M. Urbanczyk, Opt. Eng. 42, 2978 (2003).

[8] T. Pustelny, I. Zielonka, C. Tyszkiewicz, B. Pustelny, J. Jurusik, Mol. Quant. Acoust. 26, 217 (2005).

[9] T. Mazingue, L. Escoubas, L. Spalluto, F. Flory, P. Jacquoton, A. Perrone, E. Kaminska, I. Mihailescu, P. Atanasov, Appl. Opt. 45, 1425 (2007).

[10] K. Gut, K. Nowak, Europ. Phys. J.-Spec. Top. 154, 89 (2008).

[11] H.W. Kim, N.H. Kim, Mater. Sci. Eng. B 103, 297 (2003).

[12] K. Golaszewska, E. Kaminska, T. Pustelny, P. Struk, T. Piotrowski, A. Piotrowska, M. Ekielski, R. Kruszka, M. Wzorek, M. Borysewicz, I. Pasternak, K. Gut, Acta Phys. Pol. A 114, A-221 (2008).

[13] T. Pustelny, A. Opilski, B. Pustelny, Acta Phys. Pol. A 114, A-183 (2008).

[14] M. Bednorz, M. Urbanczyk, T. Pustelny, A. Piotrowska, E. Papis, Z. Sikora, E. Kaminska, Mol. Quant. Acoust. 27, 31 (2006).

[15] A. Szpakowski, C. Tyszkiewicz, T. Pustelny, Acta Phys. Pol. A 114, A-237 (2008).

[16] K. Gut, Acta Phys. Pol. A 114, A-121 (2008).

[17] T. Pustelny, I. Zielonka, C. Tyszkiewicz, P. Karasinski, B. Pustelna, Optoelectron. Rev. 46, 221 (2006).

[18] K. Gut, M. Nowak, T. Pustelny, Mol. Quant. Acoust. 28, 101 (2007). 